\title{
Plasma Zinc But Not the Exchangeable Zinc Pool Size Differs Between Young and Older Korean Women
}

\author{
Jihye Kim • Hee Young Paik • Hyojee Joung • \\ Leslie R. Woodhouse • Janet C. King
}

Received: 9 October 2009 / Accepted: 20 June 2010 /

Published online: 13 July 2010

C The Author(s) 2010. This article is published with open access at Springerlink.com

\begin{abstract}
This study was done to determine the effect of age on zinc metabolism and status among healthy Korean women. Measures of zinc metabolism and status were measured in eight young women (22-24 years) and seven elderly women (66-75 years) consuming a typical Korean diet. Oral and intravenous tracers highly enriched in ${ }^{67} \mathrm{Zn}$ and ${ }^{70} \mathrm{Zn}$ were administered simultaneously. Multiple plasma, 24-h urines, and fecal samples were collected after isotope administration. In the young women, additional plasma were collected to determine zinc kinetics using a seven-compartmental model. Exchangeable Zinc Pool (EZP) was estimated by Miller's method. Plasma zinc concentrations were higher in older women than younger women $(p<0.05)$. EZP and urinary zinc tended to be higher in older women than younger women. Fractional and total zinc absorption and endogenous fecal zinc losses did not differ between young and older women. A comparison of the zinc kinetics of the Korean and American women showed no differences in plasma or EZP zinc parameters. However, absorbed zinc and zinc flux to slowly turning over tissues (Q7) were lower in Korean women than that of Americans $(p<0.01)$ suggesting the total body zinc content of Korean women is lower than that of American women.
\end{abstract}

Reprints are not available from the author.

Presented in part at Experimental Biology 2009 in New Orleans, Louisiana, on April 21, 2009, organized by the Federation of American Societies for Experimental Biology

J. Kim

Department of Food and Nutrition, Daegu University, Gyeongbuk, South Korea

H. Y. Paik

Department of Food and Nutrition, Seoul National University, Seoul, South Korea

H. Joung

The School of Public Health, Seoul National University, Seoul, South Korea

L. R. Woodhouse

USDA/ARS Western Human Nutrition Research Center, Davis, CA, USA

J. C. King $(\bowtie)$

Children's Hospital Oakland Research Institute, 5700 Martin Luther King Jr. Way, Oakland,

CA 94609, USA

e-mail: jking@chori.org 
Keywords Zinc metabolism $\cdot$ Zinc status $\cdot$ Exchangeable zinc pool $\cdot$ Zinc kinetics $\cdot$ Age

\section{Introduction}

Zinc has an important role in nutrition and health [1]. Although dietary zinc intakes often fall below recommended levels, it is difficult to determine if low zinc intakes cause a decline in zinc status since reliable indicators of zinc status have not been identified [2]. Serum zinc concentration is commonly used to assess zinc status, but it is not ideal because many factors that are not directly related to zinc nutriture affect serum zinc concentrations [3]. The size of exchangeable zinc pools (EZPs) has been proposed as an indicator of zinc status [4]. Miller and co-workers showed that the size of the EZP varies with dietary zinc intakes in healthy adults and that the decline in EZP size varies directly with the severity of dietary zinc restriction [4]. However, few data are available on the effect of age on EZP mass even though EZP mass has been proposed as an indicator of zinc status in healthy individuals. Faure et al. [5] reported that the size of zinc pool per body weight was significantly smaller in free living elderly women $(8.1 \mu \mathrm{mol} / \mathrm{kg})$ and institutionalized women $(7.54 \mu \mathrm{mol} / \mathrm{kg})$ compared with young women $(9.71 \mu \mathrm{mol} / \mathrm{kg})$.

A mathematical model of whole body zinc metabolism provides information on zinc kinetics in multiple body pools, such as the zinc flux into the tissue and the size of the tissue zinc pool using stable isotope tracers of zinc [6, 7]. To our knowledge, a whole body kinetic study has not been done in Asians who may have different body compositions than that of a Western population.

In the present study, we compared the effect of age on measures of plasma and exchangeable pool zinc, zinc absorption, and endogenous fecal and urinary excretion in Korean women consuming about $6 \mathrm{mg}$ zinc/day. We also measured whole body zinc kinetics in young Korean women and compared the results to a similar study done in American women.

\section{Materials and Methods}

Eight healthy young women (22-24 years) and seven elderly women (66-75 years) were recruited for the study. Exclusion criteria included a body mass index of less than 17 or greater than $28 \mathrm{~kg} /$ $\mathrm{m}^{2}$, cigarette smoking, chronic use of alcohol, prescription drugs, use of oral contraceptives or vitamin or mineral supplements; a hemoglobin level $<105 \mathrm{~g} / \mathrm{L}$, the presence of acute disease or chronic disease such as diabetes, gastrointestinal disorder, and hyperlipidemia; and a reported usual dietary zinc intake $<5 \mathrm{mg} /$ day or $>15 \mathrm{mg} /$ day. All subjects gave their informed consent to participate in the study. The study protocol was reviewed and approved by the Committee on Human Research at the College of Human Ecology at Seoul National University and the Office of Human Research Protection at the University of California, Davis.

The young and older women were fed a controlled diet for 9-day metabolic period while living in a metabolic unit. On the morning of the fifth day, baseline (fasting) blood samples were drawn and the subjects then received a standard Korean breakfast with $1 \mathrm{mg}$ of ${ }^{67} \mathrm{Zn}$ in orange juice. Immediately after breakfast, $0.3 \mathrm{mg}$ of the ${ }^{70} \mathrm{Zn}$ (in $1.0 \mathrm{~mL}$ ) was infused over $1 \mathrm{~min}$ by a registered nurse. After infusion, blood samples were taken via the catheter at the following times from young women for kinetics: 5, 10, 15, 20, 30, $45 \mathrm{~min}, 1,2,4,5$, 9, and $11 \mathrm{~h}$. Additional blood samples were collected at 24, 48, 96, and $144 \mathrm{~h}$ from young women. From the elderly women, fasting blood samples were collected on days 3, 4, and 5 following isotope infusion for EZP calculation. Baseline spot urine and fecal samples were 
collected prior to the isotope infusion. Complete 24-h urine and all fecal output were collected for 5 or 9 days, respectively, following isotope administration. Fractional zinc absorption and endogenous fecal zinc losses were estimated from the isotopic tracer ratios in urines and the feces relative to urinary ratios $[8,9]$.

A two-day cycle menu of common Korean foods was used for the controlled metabolic diet (containing $6.7 \mathrm{mg} \mathrm{Zn}$ for young women) [10]. Composites of each meal were prepared for zinc and phytate analysis. The energy and protein content from study diet were determined by the estimated values from a nutrient database developed by the Korean Nutrition Society [11].

Stable isotopic tracers of zinc, highly enriched in ${ }^{67} \mathrm{Zn}(89.2 \%$ abundance $)$ or ${ }^{70} \mathrm{Zn}$ (95.56\% abundance), were purchased as zinc oxide from Trace Sciences Inc., Toronto, Canada. Diet, plasma, urine, and fecal zinc concentrations were determined by Inductively Coupled Plasma-Optical Emission Spectrophotometry (ICP-OES, Vista, Varian Inc., Walnut Creek, CA). Myo-inositol 1, 3, 4, 5, 6-pentakis-phosphate (IP5) and myo-inositol 1, 2, 3, 4, 5, 6-hexakis-phosphate (IP6) forms of dietary phytate were determined by Dionex Liquid Chromatography System (Dionex Corp., Sunnyvale, CA, USA) using a modification of the procedure by J. Lehrfeld [12]. The details for zinc and phytate analysis were described in elsewhere [13]. The zinc isotopic ratios, ${ }^{70} \mathrm{Zn} /{ }^{66} \mathrm{Zn}$, were determined in plasma, urine, and feces by ICP-Mass Spectrometry (MS), Sciex ELAN 6000 ICP-MS instrument (Perkin-Elmer, Norwalk, CT). Tracer-to-tracee ratios were calculated using the natural abundances of the various zinc isotopes and the tracer mass (in milligrams) [7].

EZP mass was calculated according into the method described by Miller et al. [4]. This method assumes that ${ }^{70} \mathrm{Zn}$ isotopes exchange with total plasma zinc at a rate that is fast enough to completely intermix within a 48 -h period. The EZP is thus equivalent to the mass of the isotope administered divided by the tracer/trace value at the $y$ intercept of the linear regression of a semilogarithmic plot of the plasma tracer/tracee data between day 3 and day 6 [days 3 to 5 for elderly women].

The kinetic model was used to analyze the tracer data, together with its input-output experimental configuration [7]. The model was determined for each subject using nonlinear least-squares parameter estimation. All tracer data sets for each subject were simultaneously fitted by using the CONSAM program $[14,15]$. The model has seven compartments. The seventh compartment (Q7) is a compartment representing irreversible loss into tissues that equilibrates very slowly with the plasma and it accounts for the loss of tracer not found in urine or feces. To estimate Q7, total body zinc mass $(\mathrm{M} 1+\mathrm{M} 2+\mathrm{M} 3+\mathrm{M} 7)$ was assumed to equal to the product of the fat-free mass of each subject (estimated at $72 \%$ of body weight) that had a zinc concentration of $30 \mathrm{mg} / \mathrm{kg}$ [16].

\section{Statistics}

The results are expressed as means \pm SD. Statistical analyses were conducted with SAS 9.1 (SAS institute Inc, Cary NC, USA). Differences in zinc parameters between young and older women or between Asian and Caucasian women were determined using a Wilcoxon rank sum test. Statistical significance is defined as $p<0.05$.

\section{Results}

Dietary zinc, body weight, and BMI were similar between young and older women. Parameters of zinc status and metabolism for the younger and older woman are described in 
Table 1. Plasma zinc concentrations $(p<0.05)$ and urinary zinc excretion $(p=0.05)$ were higher in older women than younger women. The size of the EZP and the ratio of EZP/ kilogram body weight tended to be higher in older women than younger women, but the differences did not reach significance. No differences in fractional and total zinc absorption or endogenous fecal zinc excretion occurred between the younger and older women. Fractional and total absorbed zinc significantly correlated with endogenous fecal zinc excretion in younger women ( $p<0.001$, data not shown), but this was not seen in the older women. Plasma zinc concentrations and the size of the EZP were not related to fractional or total zinc absorption or endogenous fecal zinc excretion in either group. Plasma zinc and the size of EZP were correlated with urinary zinc excretion in older women.

Whole body zinc kinetics of the younger Korean women was compared with that measured in a zinc kinetics study of American women with similar dietary zinc intakes, body weight, and BMI (Table 2). None of the parameters of plasma zinc and the exchangeable zinc pool differed between the Korean and American women. In comparison to the American women, the flux of zinc from the plasma to the very slowly turning over zinc pool, Q7, was about 38\% lower in the Korean women $(p<0.01)$. There was no difference in the flux to other more rapidly turning over zinc pools (Q2 and Q3, data not shown). Total absorbed zinc and fractional zinc absorption tended to differ between Korean women and American women.

\section{Discussion}

Plasma zinc concentration in older Korean women who consumed a habitual diet containing $6 \mathrm{mg}$ zinc/day was 32\% higher than that of the younger Korean women consumed similar amounts of dietary zinc. However, no changes were found in zinc absorption or endogenous fecal excretion. EZP mass did not differ between young women and older women. Aging affected zinc status, as measured by plasma zinc concentration, but did not affect zinc status, as measured by EZP mass. This suggest that EZP mass can be used as an indicator of zinc status in older individuals. This finding is in contrast with the results of previous studies. Faure et al. [5] reported that EZP size was smaller in elderly women (average age: 72 years) compared to young women (average age: 36 years) with very similar zinc intake. A zinc supplementation study showed that EZP was negatively correlated with age of subjects in late-middle-aged population (58-68 years) [17]. Lower EZP mass in elderly subjects might be due to lower fat-free mass in elderly subjects since

Table 1 Plasma and Exchangeable Zinc Pool, Zinc Absorption, and Endogenous Fecal and Urinary Excretion in Young and Older Korean Women (Mean \pm SD)

\begin{tabular}{lcc}
\hline Zinc Measures & Young Women $(n=8)$ & Older Women $(n=7)$ \\
\hline Plasma Zn (mg/L) & $0.6 \pm 0.1^{*}$ & $0.8 \pm 0.1$ \\
Exchangeable Zn Pool (mg) & $110 \pm 18$ & $129 \pm 17$ \\
Exchangeable Zn Pool (mg/kg body weight) & $1.1 \pm 0.2$ & $2.2 \pm 0.4$ \\
Fractional Zn Absorption (\%) & $23 \pm 4$ & $21 \pm 6$ \\
Total Absorbed Zn (mg/day) & $1.5 \pm 0.3$ & $1.3 \pm 0.4$ \\
Endogenous Fecal Zn (mg/day) & $1.4 \pm 0.3$ & $1.8 \pm 0.4$ \\
Urinary Zn ( $\mu \mathrm{g} /$ day) & $165 \pm 93^{* *}$ & $325 \pm 144$ \\
\hline
\end{tabular}

${ }^{*} p<0.05 ; * *=0.05$ (mean values are significantly different between young women and older women) 
Table 2 A Comparison of Whole Body Zinc Kinetics in Asian and Caucasian Women Consuming Similar Amounts of Dietary Zinc

\begin{tabular}{lcc}
\hline Zinc Measures & Asian Women $(n=8)$ & Caucasian Women [7] $(n=6)$ \\
\hline Plasma zinc (mg/L) & $0.6 \pm 0.1$ & $0.7 \pm 0.1$ \\
Plasma mass (mg) & $1.8 \pm 0.3$ & $2.0 \pm 0.1$ \\
Plasma turnover (times/day) & $119 \pm 16$ & $132 \pm 36$ \\
Plasma zinc flux (mg/day) & $207 \pm 45$ & $267 \pm 73$ \\
EZP (mg) & $99 \pm 29$ & $87 \pm 16$ \\
EZP/body weight (mg/kg) & $1.8 \pm 0.5$ & $1.6 \pm 0.1$ \\
Flux to EZP (mg/day) & $197 \pm 44$ & $249 \pm 72$ \\
Q7 (mg) & $1,099 \pm 150$ & $1,083 \pm 178$ \\
Flux to Q7 (mg/day) & $9.2 \pm 1.7^{*}$ & $14.7 \pm 2.9$ \\
Fractional zinc absorption (\%) & $23 \pm 4$ & $30 \pm 11$ \\
Total absorbed zinc (mg/day) & $1.5 \pm 0.3$ & $2.1 \pm 0.7$ \\
Endogenous zinc excretion (mg/day) & $1.4 \pm 0.3$ & $1.9 \pm 0.5$ \\
Urinary zinc ( $\mu$ g/day) & $165 \pm 93$ & $210 \pm 122$ \\
\hline
\end{tabular}

$E Z P$ exchangeable zinc pool, $Q 7$ the size of the very slowly turning over pool

${ }^{*} p<0.01$ (mean values are significantly different between Asian women and Caucasian women)

zinc is observed in lean tissue as a part of protein mass. EZP mass is positively correlated with fat-free mass [18]. Unfortunately, we did not measure fat-free mass in older women. On the other hand, Griffin et al. [19] demonstrated that body-weighted-corrected mass of the body zinc were significantly greater in children than those in adults suggesting the differences in zinc metabolism with age. They explained that the amounts of labile zinc would increase to support the rapid growth in lean tissue mass among children.

Plasma zinc concentration in older women was higher than that of younger women in this study although plasma zinc mostly found to be lower in elderly subjects [20, 21]. Possibly, the absorbed zinc might be distributed differently within some tissues of older women compared to younger women. Wastney et al. [22] demonstrated the altered zinc distribution with age among men and women aged 20-84 years consuming their habitual diet containing $10 \mathrm{mg} \mathrm{Zn/day} \mathrm{for} 9$ months. Under normal zinc intake, the release of zinc from red blood cells (RBC) decreased by $35 \%$ with a $74 \%$ increase in RBC compartment and fractions of rapidly turning over zinc in liver increased with age by $13 \%$, while zinc in thigh muscle decreased by $75 \%$. Increase in liver zinc in older women may reflect increased plasma zinc since most liver zinc is in rapid equilibrium with plasma [23]. The previous studies have also shown that the distribution of absorbed zinc might change with age $[8,9]$. Kim et al. [8] reported that plasma and urinary zinc concentration significantly increased with zinc supplementation in the young women, but not in elderly women suggesting that age altered the use of additionally absorbed zinc from supplements.

A comparison of the zinc kinetics of the Korean and American women showed no differences in plasma or EZP zinc parameters. In comparison to American women, the young Korean women absorbed less zinc and transferred less zinc to the slowly turning over body zinc pool suggesting that the total body zinc content of the Korean women may be lower than that of their American women. Lower body zinc content in Korean women may be due to lower mass of muscle and bone in Korean women compared with American women. Since the slowly turning over body zinc pool (Q7) reflects uptake of the tracer by muscle and bone, the shift of less zinc to Q7 present the lower lean body mass in Korean 
women. Asians have lower proportion of lean tissue compared to Caucasians although both women had similar BMI [24, 25]. Asian Indians had a distinct body composition with excess body fat, abdominal adiposity, and less lean mass at the range of BMI considered normal [24]. Wang et al. [25] reported that Asians had higher body fat than Whites in both genders although Asians had lower BMI.

Our study has a limitation. Because of the small number of subjects, we might have not observed significant differences between two groups of women classified by age or ethnicity. However, this study is a very well-controlled human metabolism study although it is lacking of statistical power.

In conclusion, the zinc status of older Korean women, as measured by plasma zinc concentration was higher than that of the younger women. However, there were no changes in EZP size between two age groups of women. Further studies on zinc kinetics in older individuals are needed to understand the changes of zinc metabolism with age. In comparison to American women, the young Korean women absorbed less zinc and transferred less zinc to the slowly turning over body zinc pool. This suggests that the total body zinc content of the Korean women is lower than that of their American women.

Acknowledgment The study was funded by National Research Foundation of Korea and USDA/ARS Western Human Nutrition Research Center.

Disclosure statement The authors declare that they have no competing interests.

Open Access This article is distributed under the terms of the Creative Commons Attribution Noncommercial License which permits any noncommercial use, distribution, and reproduction in any medium, provided the original author(s) and source are credited.

\section{References}

1. Coudray C, Feillet-Coudray C, Rambeau M et al (2006) The effect of aging on intestinal absorption and status of calcium, magnesium, zinc, and copper in rats: a stable isotope study. J Trace Elem Med Biol 20:73-81

2. King JC (1990) Assessment of zinc status. J Nutr 120(Suppl 11):1474-1479

3. Solomons NW, Jacob RA (1981) Studies on the bioavailability of zinc in humans: effects of heme and nonheme iron on the absorption of zinc. Am J Clin Nutr 34:475-482

4. Miller LV, Hambidge KM, Naake VL et al (1994) Size of the zinc pools that exchange rapidly with plasma zinc in humans: alternative techniques for measuring and relation to dietary zinc intake. J Nutr 124:268-276

5. Faure P, Ducros V, Couzy F et al (2005) Rapidly exchangeable pool study of zinc in free-living or institutionalized elderly women. Nutrition 21:831-837

6. King JC, Shames DM, Lowe NM et al (2001) Effect of acute zinc depletion on zinc homeostasis and plasma zinc kinetics in men. Am J Clin Nutr 74:116-124

7. Lowe NM, Shames DM, Woodhouse LR et al (1997) A compartmental model of zinc metabolism in healthy women using oral and intravenous stable isotope tracers. Am J Clin Nutr 65:1810-1819

8. Kim J, Paik HY, Joung H et al (2004) Zinc supplementation reduces fractional zinc absorption in young and elderly Korean women. J Am Coll Nutr 23:309-315

9. Kim J, Paik HY, Joung H et al (2007) Effect of dietary phytate on zinc homeostasis in young and elderly Korean women. J Am Coll Nutr 26:1-9

10. Kim J, Woodhouse LR, King JC et al (2009) Relationships between faecal phytate and mineral excretion depend on dietary phytate and age. Br J Nutr 102:835-841

11. The Korean Nutrition Society (2000) Recommended Dietary Allowances for Koreans, 7 th revision, Seoul

12. Lehrfeld J (1994) HPLC separation and quantification of phytic acid and some inositol phosphates in foods: problems and solutions. J Agric Food Chem 42:2726-2731 
13. Joung H, Jeun BY, Li SJ et al (2007) Fecal phytate excretion varies with dietary phytate and age in women. J Am Coll Nutr 26:295-302

14. Berman M, Beltz WF, Grief PC et al (1983) CONSAM users guide. US Department of Health and Human Services, Public Health Service, National Institute of Health, Bethesda, MD

15. Berman M, Weiss MF (1978) SAAM manual. US Government Printing Office, Washington DC

16. Forbes GB (1987) Human body composition :growth, aging, nutrition, and activity. Springer-Verlag, New York

17. Feillet-Coudray C, Meunier N, Rambeau M et al (2005) Long-term moderate zinc supplementation increases exchangeable zinc pool masses in late-middle-aged men: the Zenith Study. Am J Clin Nutr $82: 103-110$

18. Pinna K, Woodhouse LR, Sutherland B et al (2001) Exchangeable zinc pool masses and turnover are maintained in healthy men with low zinc intakes. J Nutr 131:2288-2294

19. Griffin IJ, King JC, Abrams SA (2000) Body weight-specific zinc compartmental masses in girls significantly exceed those reported in adults: a stable isotope study using a kinetic model. J Nutr 130:2607-2612

20. De Jong N, Gibson RS, Thomson CD et al (2001) Selenium and zinc status are suboptimal in a sample of older New Zealand women in a community-based study. J Nutr 131:2677-2684

21. Turnlund JR, Durkin N, Costa F et al (1986) Stable isotope studies of zinc absorption and retention in young and elderly men. J Nutr 116:1239-1247

22. Wastney ME, Ahmed S, Henkin RI (1992) Changes in regulation of human zinc metabolism with age. Am J Physiol 263:R1162-R1168

23. Wastney ME, Aamodt RL, Rumble WF et al (1986) Kinetic analysis of zinc metabolism and its regulation in normal humans. Am J Physiol 251:R398-R408

24. Misra A (2003) Impact of ethnicity on body fat patterning in Asian Indians and blacks: relation with insulin resistance. Nutrition 19:815-816

25. Wang J, Thornton JC, Russell M et al (1994) Asians have lower body mass index (BMI) but higher percent body fat than do whites: comparisons of anthropometric measurements. Am J Clin Nutr 60:23-28 